\title{
Cadmium induces plasminogen activator inhibitor-1 via Smad2/3 signaling pathway in human endothelial EA.hy926 cells
}

\author{
Takato Hara1, Miki Sakuma1, Tomoya Fujie1, Toshiyuki Kaji² and Chika Yamamoto1 \\ ${ }^{1}$ Faculty of Pharmaceutical Sciences, Toho University, 2-2-1 Miyama, Funabashi, Chiba 274-8510, Japan \\ ${ }^{2}$ Faculty of Pharmaceutical Sciences, Tokyo University of Science, 2641 Yamazaki, Noda, Chiba 278-8510, Japan
}

(Received March 18, 2021; Accepted March 22, 2021)

\begin{abstract}
Modulation of the blood coagulation fibrinolytic system is an essential function of vascular endothelial cells. Tissue plasminogen activator (t-PA) and plasminogen activator inhibitor-1 (PAI-1) are major fibrinolytic regulatory proteins synthesized by vascular endothelial cells; fibrinolytic activity is dependent on the balance between these proteins. Previously, we have reported that cadmium, an initiator of ischemic heart disease, induces PAI-1 expression and suppresses fibrinolytic activity in cultured human vascular endothelial cells. However, the key molecules involved in cadmium-induced PAI-1 induction remain unclear. Herein, we investigated the contribution of Smad2 and Smad3, transcriptional factors involved in PAI-1 induction via transforming growth factor- $\beta$, using the human vascular endothelial cell line EA.hy926 cells in culture. Our findings indicated that cadmium induces PAI-1 expression without affecting t-PA expression up to $20 \mu \mathrm{M}$, a non-cytotoxic concentration, and PAI-1 induction by cadmium is partly mediated via Smad2 and Smad3. This study provides a possible mechanism underlying cadmiuminduced vascular disorders.
\end{abstract}

Key words: Fibrinolysis, Plasminogen activator inhibitor-1, Cadmium, Vascular endothelial cell

\section{INTRODUCTION}

Unintentional exposure to cadmium, a heavy metal, is known to occur via diet and smoking habits. Animal and epidemiological studies have indicated that cadmium is a risk factor for atherosclerosis (Tellez-Plaza et al., 2012; Fagerberg et al., 2015; Messner et al., 2009; Oliveira et al., 2019). Furthermore, atherosclerotic regions are prone to ischemic heart diseases associated with thrombus formation. Regulation of the blood coagulation-fibrinolytic system is an important function of vascular endothelial cells that sheath the lumen of blood vessels. Tissue plasminogen activator (t-PA) and plasminogen activator inhibitor-1 (PAI-1) are major fibrinolytic modulators synthesized by vascular endothelial cells. Since fibrinolysis is dependent on the balance between t-PA and PAI-1 activities, t-PA predominance enhances fibrinolysis by converting plasminogen to plasmin, whereas PAI-1 predominance suppresses fibrinolysis (Levin and Loskutoff, 1982; Gross et al., 1982; van Mourik et al., 1984). The risk of ischemic heart disease is increased as decreased fibrinolytic activity prevents the dissolution of intravascular thrombi.

Previously, we reported that cadmium suppresses fibrinolytic activity by specifically inducing PAI-1 mRNA levels without affecting t-PA expression (Yamamoto et al., 1993; Yamamoto and Kaji, 2002). However, the transcriptional factors involved in the induction of PAI-1 expression via cadmium remain unknown. Smad2 and Smad3 are transcriptional factors that activate transforming growth factor- $\beta$ (TGF- $\beta$ ) and are involved in PAI-1 expression (Yingling et al., 1997; $\mathrm{Xu}$ et al., 2000). Additionally, some studies have reported that cadmium activates Smad2/3 signaling (Das et al., 2019; Li et al., 2017). In the present study, we investigated the role of Smad2/3 signaling in reducing fibrinolytic activity induced by cadmium by using the umbilical vein endothelial cell line, EA.hy926 cells in a culture system.

Correspondence: Chika Yamamoto (E-mail: yamamoto@phar.toho-u.ac.jp) 


\section{MATERIALS AND METHODS}

\section{Materials}

The human endothelial cell line, EA.hy926, was purchased from ATCC (Manassas, VA, USA). Tissue culture dishes and plates were obtained from AGC Techno Glass (Shizuoka, Japan). Dulbecco's modified Eagle's medium (DMEM) and $\mathrm{Ca}^{2+}$ - and $\mathrm{Mg}^{2+}$-free phosphate-buffered saline (CMF-PBS) were obtained from Nissui Pharmaceutical (Tokyo, Japan). Fetal bovine serum (FBS), Lipofectamine RNAiMAX, a bicinchoninic acid protein assay kit, and a High-Capacity cDNA Reverse Transcription kit were purchased from Thermo Fisher Scientific (Waltham, MA, USA). 3-(4,5-Dimethyl-2-thiazolyl)-2,5-diphenyl-2Htetrazolium bromide (MTT) was purchased from Dojindo Laboratories (Kumamoto, Japan). Fibrinogen and thrombin from human plasma were purchased from Sigma-Aldrich (St. Louis, MO, USA). Enzyme-linked immunosorbent assay (ELISA) kits for human t-PA and PAI-1 were purchased from Assaypro LLC (St. Charles, MO, USA). ISOGEN-II, GeneAce SYBR qPCR mix $\alpha$, and negative control siRNA were purchased from Nippon Gene (Tokyo, Japan). Anti-Smad2/3 (\#8685), antiphospho-Smad2/3 (\#8828) antibodies and HRPconjugated anti-rabbit and mouse IgG secondary antibodies (\#7074 and \#7076, respectively) were obtained from Cell Signaling Technology (Beverly, MA, USA). Anti- $\beta$-actin antibody (60008-1-Ig) was purchased from Proteintech (Rosemont, IL, USA). Amersham $^{\mathrm{TM}}$ Hybond ${ }^{\mathrm{TM}} \mathrm{P}$ PVDF 0.2 was obtained from GE Healthcare UK Ltd. (Amersham Place, UK). Cadmium chloride, Chemi-Lumi One Super, and other reagents of the highest grade available were obtained from Nacalai Tesque (Kyoto, Japan).

\section{Cell culture and treatments}

EA.hy926 cells were cultured in a humidified atmosphere of $5 \% \mathrm{CO}_{2}$ at $37^{\circ} \mathrm{C}$ in DMEM supplemented with $10 \%$ FBS until confluence. Then, cells were transferred into 6-, 24-, or 96-well culture plates and cultured until confluence, with the following experiments then performed.

\section{siRNA transfection}

The transient transfection of siRNAs was performed using Lipofectamine RNAiMAX, as described previously with (Hara et al., 2017), minor modifications. In brief, EA.hy926 cells in 6-well plates were grown to approximately $80 \%$ confluence in DMEM supplemented with $10 \% \mathrm{FBS}$ and incubated for $24 \mathrm{hr}$ at $37^{\circ} \mathrm{C}$ in fresh
DMEM supplemented with 10\% FBS and the siRNA/ Lipofectamine RNAiMAX mixture. The final concentrations of siRNA and Lipofectamine RNAiMAX were $20 \mathrm{nM}$ and $0.1 \%$, respectively. The sequences of the sense and antisense strands of siRNAs are listed in our previous report (Hara et al., 2017). Native control siRNA (siCont.) was used as a non-specific sequence.

\section{Cell viability assay}

In brief, the medium was discarded, and cells in 96-well culture plates were washed with serum-free DMEM. Next, the cells were treated with cadmium $(1,5,10,15,20,25,30,35,40$, and $45 \mu \mathrm{M})$ for $24 \mathrm{hr}$. After treatment, the conditioned medium was discarded, and the cell layer was washed with CMF-PBS, with the MTT assay performed as previously described (Hara et al., 2018). The $50 \%$ cytotoxic concentration $\left(\mathrm{CC}_{50}\right)$ was defined as the concentration at which the cell viability decreased by $50 \%$, calculated using a fitted logit formula using ImageJ software (National Institutes of Health, Bethesda, MD, USA). In another experiment, May-Grünwald Giemsa staining was performed on cells in a 6-well culture plate for morphological observation.

\section{Fibrin zymography}

Fibrin zymography was performed as described previously (Yamamoto et al., 2005), with minor modifications. The medium was discarded, and the cells in 24-well culture plates were washed with serum-free DMEM. Then, cells were treated with cadmium $(1,5,10,15$, and $20 \mu \mathrm{M})$ for $24 \mathrm{hr}$. After treatment, the conditioned medium was collected and incubated with loading buffer (the final concentration; $0.05 \mathrm{M}$ Tris, $8 \mathrm{v} / \mathrm{v} \%$ glycerol, $0.67 \%$ sodium dodecyl sulfate [SDS], and $0.002 \%$ bromophenol blue) for $1 \mathrm{hr}$ at $37^{\circ} \mathrm{C}$ under non-reducing condition. The samples were separated by SDS-polyacrylamide gel electrophoresis (PAGE) on a 7.5\% slab gel with a $4.5 \%$ stacking gel. The slab gel containing fibrin was prepared using plasminogen-rich fibrinogen $(0.5 \mathrm{mg} / \mathrm{mL})$ and thrombin (0.017 NIH U/mL). After SDS-PAGE, the gel was washed twice with $2.5 \%$ Triton X-100 for $30 \mathrm{~min}$ and incubated for $24 \mathrm{hr}$ at $37^{\circ} \mathrm{C}$ in $0.1 \mathrm{M}$ glycine- $\mathrm{NaOH}$ buffer solution ( $\mathrm{pH} 8.3$ ). Then, the gel was stained with $0.25 \%$ Coomassie brilliant blue and destained with $7.5 \%$ acetic acid until the lytic zone was clear.

\section{Measurement of t-PA and PAI-1 secretion}

Next, t-PA and PAI-1 secretions were examined using the conditioned medium of EA.hy926 cells in 24-well culture plates treated with cadmium $(1,5,10,15$, and $20 \mu \mathrm{M})$ for $24 \mathrm{hr}$ with specific ELISA kits, expressed as $\mu \mathrm{g} / \mathrm{well}$. 
Smad2/3 independent PAI-1 induction by cadmium

Table 1. Gene-specific primers for quantitative RT-PCR.

\begin{tabular}{lll}
\hline Gene & \multicolumn{1}{c}{ Forward primer $\left(5^{\prime}-3^{\prime}\right)$} & \multicolumn{1}{c}{ Reverse primer $\left(5^{\prime}-3^{\prime}\right)$} \\
\hline t-PA & GGCAAGGTTTACACAGCACAG & CCCATCAGGATTCCGGCAG \\
PAI-1 & GCCAGTGGAAGACTCCCTTC & GGGCGTGGTGAACTCAGTATAG \\
$\beta$-actin & CCAGCTCACCATGGATGATG & ATGCCGGAGCCGTTGTC \\
\hline
\end{tabular}

\section{Total RNA extraction and quantitative RT-PCR}

Total RNA was extracted according to the manufacturer's protocol. Briefly, the medium was discarded, and cells in 6-well culture plates were washed with serum-free DMEM. Then, cells were treated with cadmium $(1,5,10$, 15 , or $20 \mu \mathrm{M}$ ) for $24 \mathrm{hr}$. After treatment, the conditioned medium was discarded, and $300 \mu \mathrm{L}$ of cold ISOGENII was added to each well. The cells were then homogenized by pipetting. Next, $120 \mu \mathrm{L}$ of ultrapure water was added to the collected homogenate and incubated for $5 \mathrm{~min}$. The samples were centrifuged at $4{ }^{\circ} \mathrm{C}$ at $15,000 \times g$ for 15 min with $300 \mu \mathrm{L}$ of the collected supernatant and mixed with $300 \mu \mathrm{L}$ of 2-propanol. After incubation for $5 \mathrm{~min}$, the samples were centrifuged at $4^{\circ} \mathrm{C}$ for $15 \mathrm{~min}$ at $15,000 \times g$. The supernatant was discarded, and the RNA pellet was washed with $70 \%$ ethanol. Finally, the RNA pellets were dissolved in ultrapure water. cDNA was synthesized from total RNA using a High-Capacity cDNA Reverse Transcription kit. Quantitative PCR was performed using GeneAce SYBR qPCR mix $\alpha$ with $1 \mathrm{ng}$ cDNA and $0.2 \mu \mathrm{M}$ of primers (Table 1) on a CFX Connect Real-Time PCR Detection System (BioRad, Hercules, CA, USA). The levels of t-PA, PAI-1, Smad2, Smad3, and $\beta$-actin transcripts were quantified using the relative standard curve method. The fold change in the intensity value of the target gene was normalized to that of $\beta$-actin.

\section{Western blotting}

Smad $2 / 3$ and $\beta$-actin proteins were separated by SDSPAGE, and western blotting was performed as described previously (Takahashi et al., 2018). Immunoreactive bands were visualized using Chemi-Lumi One Super western blot detection reagent and scanned using an Amersham Imager 600 (GE Healthcare).

\section{Statistical analysis}

Data were analyzed to assess statistical significance by analysis of variance and Bonferroni's multiple $t$-tests, when applicable. Statistical significance was set at $p<0.05$.

\section{RESULTS AND DISCUSSION}

To eliminate the effect of non-specific cytotoxicity in subsequent experiments, we first examined the cadmium concentration at which cytotoxicity was observed in EA.hy926 cells. The viability of EA.hy926 cells was significantly reduced following cadmium exposure at $25 \mu \mathrm{M}$ or higher, and $\mathrm{CC}_{50}$ was calculated as $27.94 \mu \mathrm{M}$ (Fig. 1A). Furthermore, no morphological changes were observed in cells after $24 \mathrm{hr}$ of cadmium exposure at concentrations less than $20 \mu \mathrm{M}$ (Fig. 1B).

Next, we analyzed the effect of cadmium on t-PA and PAI-1 expression in EA.hy926 cells. As shown in Fig. 2A, t-PA activity was suppressed by cadmium in

[A]

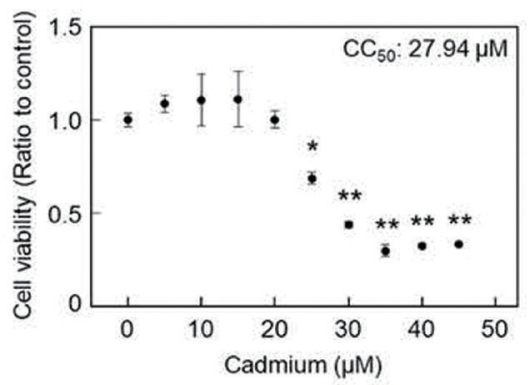

[B]

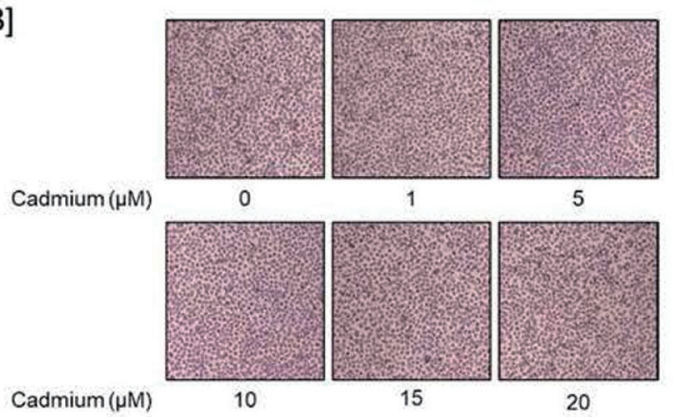

Fig. 1. The cytotoxicity of cadmium in vascular endothelial cells. Confluent EA.hy926 cells were exposed to cadmium at $1,5,10,15,20,25,30,35,40$, or $45 \mu \mathrm{M}$ for $24 \mathrm{hr}$ and [A] cell viability and [B] morphology were assessed. Values represent means \pm S.E. of four experimental samples. Significantly different from the control, $* p<0.05$ and $* * p<0.01$. The $50 \%$ cytotoxic concentration $\left(\mathrm{CC}_{50}\right)$ is defined as the concentration where cell viability decreases by $50 \%$. 
T. Hara et al.

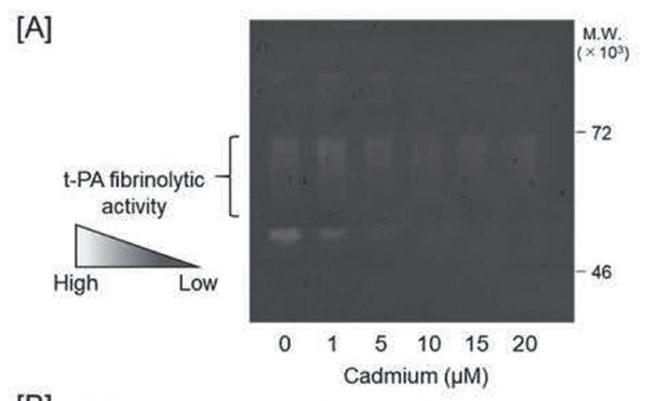

[B]
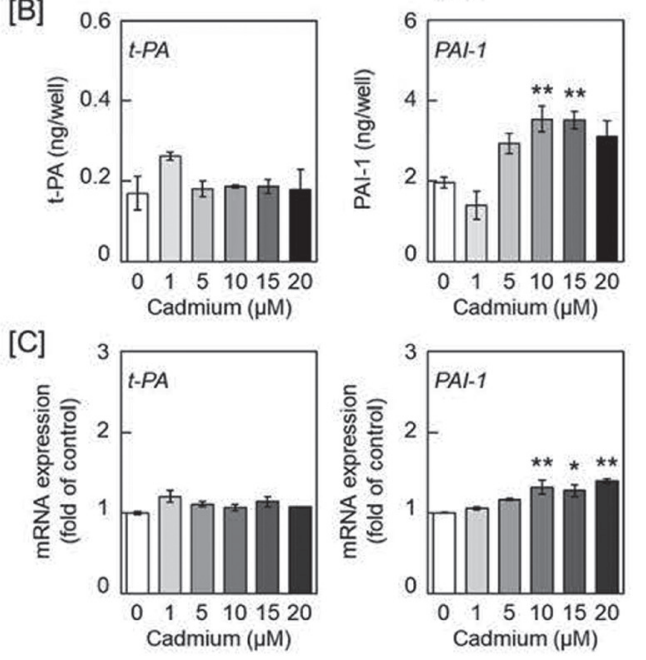

Fig. 2. Cadmium suppresses t-PA fibrinolytic activity via PAI-1 induction in vascular endothelial cells. Confluent EA.hy926 cells were exposed to cadmium at 1,5 , 10,15 , and $20 \mu \mathrm{M}$ for $24 \mathrm{hr}$ and [A] fibrinolytic activity, [B] protein secretion, [C] mRNA expression were analyzed. Values represent the mean \pm S.E. of three technical replicates. Significantly different from the control, ${ }^{*} p<0.05$ and $* * p<0.01$.

a dose-dependent manner. Based on ELISA analysis, the cadmium-induced suppression of t-PA activity was caused by enhanced PAI- 1 secretion into the conditioned medium, but not by reduced t-PA (Fig. 2B). Furthermore, cadmium selectively and dose-dependently induced only PAI-1 mRNA expression without affecting t-PA mRNA expression (Fig. 2C). These results are consistent with our previous report using cultured human umbilical vascular endothelial cells (Yamamoto and Kaji, 2002; Yamamoto et al., 1993).

Since Smad2 and Smad3 are major transcription factors that upregulate PAI-1 mRNA expression (Yingling et al., 1997; Xu et al., 2000), we investigated whether Smad 2 and Smad3 are activated by cadmium and are involved in cadmium-induced upregulation of PAI-1

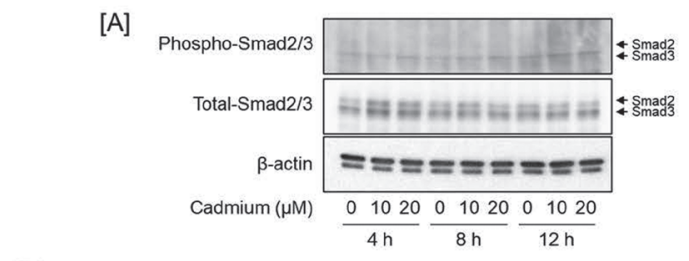

[B]
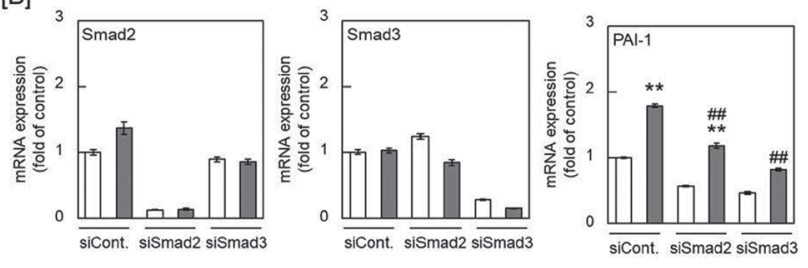

Fig. 3. Cadmium-induced PAI-1 expression is mediated by Smad2/3 in vascular endothelial cells. [A] Confluent EA.hy926 cells were exposed to cadmium at 10 and $20 \mu \mathrm{M}$ for 4,8 , and $12 \mathrm{hr}$ and the phosphorylation of Smad2/3 was detected. [B] Smad2 (siSmad2)- or Smad3 (siSmad3)-knocked down EA.hy926 cells were exposed to $10 \mu \mathrm{M}$ cadmium for $24 \mathrm{hr}$ and mRNA expression was analyzed. Values represent the mean \pm S.E. of three technical replicates. ${ }^{* *} p<0.01$ vs. siCont without cadmium exposure; ${ }^{\#} p<0.01$ vs. siCont exposed to cadmium.

mRNA. Smad3 was activated following cadmium exposure for $12 \mathrm{hr}$ (Fig. 3A). Although Smad2 was expressed in EA.hy926 cells, its activated state was weaker than that of Smad3 (Fig. 3A). To examine the involvement of Smad2 and Smad3 in PAI-1 induction by cadmium, EA.hy926 cells were transfected with Smad2 and Smad3 siRNA and then exposed to cadmium. Herein, we observed that Smad2 and Smad3 siRNA transfection partly inhibited cadmium-induced PAI-1 mRNA expression, and the suppression efficiency of PAI-1 was higher with Smad3 knockdown than with Smad2 (Fig. 3B). Specifically, after $24 \mathrm{hr}$ of incubation in the absence of cadmium, PAI- 1 mRNA expression was suppressed to $56 \%$ and $46 \%$ in Smad 2 and Smad3-knockdowned cells, respectively, compared with the control siRNA-transfected cells. Our findings that knockdown of Smad2 and Smad3 reduced the PAI-1 mRNA expression indicated that the basal level of PAI-1 mRNA was maintained by both Smad2 and Smad3.

In the present study, we observed that cadmium suppressed fibrinolytic activity in EA.hy926 cells by inducing the expression of PAI-1 through the activation of Smad2 and Smad3. Our previous report suggested that the induction of PAI-1 by cadmium is mediated via protein kinase C (Yamamoto and Kaji, 2002); the present 
Smad2/3 independent PAI-1 induction by cadmium

study revealed that transcriptional factors $\operatorname{Smad} 2$ and Smad3 are partly responsible for this induction. Although the relationship between the protein kinase C and Smad signaling in the induction of PAI-1 expression by cadmium remains elusive, these studies provide a molecular mechanism for cadmium-induced vascular dysfunction.

\section{ACKNOWLEDGMENTS}

This work was supported by JSPS KAKENHI Grant Number JP 18K06638 (to C.Y.).

Conflict of interest---- The authors declare that there is no conflict of interest.

\section{REFERENCES}

Das, S., Dewanjee, S., Dua, T.K., Joardar, S., Chakraborty, P., Bhowmick, S., Saha, A., Bhattacharjee, S. and De Feo, V. (2019): Carnosic acid attenuates cadmium induced nephrotoxicity by inhibiting oxidative stress, promoting Nrf2/HO-1 signalling and impairing TGF- $\beta 1 / \mathrm{Smad} /$ collagen IV signalling. Molecules, 24, 4176.

Fagerberg, B., Barregard, L., Sallsten, G., Forsgard, N., Ostling, G., Persson, M., Borné, Y., Engström, G. and Hedblad, B. (2015): Cadmium exposure and atherosclerotic carotid plaques--results from the Malmö diet and Cancer study. Environ. Res., 136, 6774.

Gross, J.L., Moscatelli, D., Jaffe, E.A. and Rifkin, D.B. (1982): Plasminogen activator and collagenase production by cultured capillary endothelial cells. J. Cell Biol., 95, 974-981.

Hara, T., Nonaka, Y., Yasuike, S., Kaji, T. and Yamamoto, C. (2018): Structure-activity relationship of [1,5]azastibocines in cytotoxicity to vascular endothelial cells. J. Toxicol. Sci., 43, 735-740.

Hara, T., Yoshida, E., Fujiwara, Y., Yamamoto, C. and Kaji, T. (2017): Transforming growth factor-beta1 modulates the expression of syndecan-4 in cultured vascular endothelial cells in a biphasic manner. J. Cell. Biochem., 118, 2009-2017.

Levin, E.G. and Loskutoff, D.J. (1982): Cultured bovine endothelial cells produce both urokinase and tissue-type plasminogen activators. J. Cell Biol., 94, 631-636.

Li, F.J., Surolia, R., Li, H., Wang, Z., Liu, G., Liu, R.M., Mirov, S.B., Athar, M., Thannickal, V.J. and Antony, V.B. (2017): Lowdose cadmium exposure induces peribronchiolar fibrosis through site-specific phosphorylation of vimentin. Am. J. Physiol. Lung Cell. Mol. Physiol., 313, L80-L91.

Messner, B., Knoflach, M., Seubert, A., Ritsch, A., Pfaller, K., Henderson, B., Shen, Y.H., Zeller, I., Willeit, J., Laufer, G., Wick, G., Kiechl, S. and Bernhard, D. (2009): Cadmium is a novel and independent risk factor for early atherosclerosis mechanisms and in vivo relevance. Arterioscler. Thromb. Vasc. Biol., 29, 1392-1398.

Oliveira, T.F., Batista, P.R., Leal, M.A., Campagnaro, B.P., Nogueira, B.V., Vassallo, D.V., Meyrelles, S.S. and Padilha, A.S. (2019): Chronic cadmium exposure accelerates the development of atherosclerosis and induces vascular dysfunction in the aorta of ApoE(-/-) mice. Biol. Trace Elem. Res., 187, 163-171.

Takahashi, A., Takahashi, M., Fujie, T., Hara, T., Yoshida, E., Yamamoto, C. and Kaji, T. (2018): A zinc complex that suppresses the expression of a reactive sulfur species-producing enzyme, cystathionine $\gamma$-lyase, in cultured vascular endothelial cells. Fundam. Toxicol. Sci., 5, 181-184.

Tellez-Plaza, M., Navas-Acien, A., Menke, A., Crainiceanu, C.M., Pastor-Barriuso, R. and Guallar, E. (2012): Cadmium exposure and all-cause and cardiovascular mortality in the U.S. general population. Environ. Health Perspect., 120, 1017-1022.

van Mourik, J.A., Lawrence, D.A. and Loskutoff, D.J. (1984): Purification of an inhibitor of plasminogen activator (antiactivator) synthesized by endothelial cells. J. Biol. Chem., 259, 1491414921.

Xu, W., Angelis, K., Danielpour, D., Haddad, M.M., Bischof, O., Campisi, J., Stavnezer, E. and Medrano, E.E. (2000): Ski acts as a co-repressor with $\mathrm{Smad} 2$ and $\mathrm{Smad} 3$ to regulate the response to type beta transforming growth factor. Proc. Natl. Acad. Sci. USA, 97, 5924-5929.

Yamamoto, C. and Kaji, T. (2002): Induction of plasminogen activator inhibitor type 1 synthesis by cadmium in human vascular endothelial cells in culture. J. Health Sci., 48, 55-61.

Yamamoto, C., Kaji, T., Sakamoto, M. and Kozuka, H. (1993): Cadmium stimulation of plasminogen activator inhibitor-1 release from human vascular endothelial cells in culture. Toxicology, 83, 215-223.

Yamamoto, C., Sugato, M., Fujiwara, Y. and Kaji, T. (2005): Selective promotion of plasminogen activator inhibitor-1 secretion by activation of proteinase-activated receptor-1 in cultured human brain microvascular pericytes: comparison with endothelial cells. Biol. Pharm. Bull., 28, 208-211.

Yingling, J.M., Datto, M.B., Wong, C., Frederick, J.P., Liberati, N.T. and Wang, X.F. (1997): Tumor suppressor Smad4 is a transforming growth factor beta-inducible DNA binding protein. Mol. Cell. Biol., 17, 7019-7028. 